\title{
STUDY ON THE DETERMINING FACTORS TO MAINTAIN A QUALITY EDUCATION IN TIMES OF THE COVID-19 PANDEMIC
}

\author{
Vicente Guerola-Navarro, Raúl Oltra-Badenes, Hermenegildo Gil-Gomez \\ Departamento de Organización de Empresas. Universitat Politècnica de València (SPAIN)
}

\begin{abstract}
Within the actual academic environment that has led (due to mobility restrictions and social distancing imposed by the health emergency as a result of the COVID-19 pandemic) to online teaching, students and teachers have had to adapt their coexistence and learning parameters. After an academic semester of changing the teaching model, and with the vital experience of students and teachers, the students from a highly representative university subject have been asked to fulfill a questionnaire for evaluating which have been the initiatives or actions that have helped them the most to obtain and value the education received in the University as inclusive and of quality. This links and responds to the pursuit of Sustainable Development Goal (SDG) number 4, defined as the United Nations (UN) as "Quality Education".

To carry out the study, a last-year university degree subject has been selected (to ensure that the students are mature), where an online course has already been taught (to ensure that they have already lived the experience and have criteria and valuable proposals for improvement), a subject with a highly interactive character (where the online format may require a greater change of approach), and with a high number of students. The subject that has been selected for the study has been "Organizational Behavior and Change Management", that is an optional subject in the last year of the Computer Engineering Degree and double Degree with Business Administration and Management, which is taught at the Higher Polytechnic School of Alcoy (EPSA). This subject is focused on the knowledge and practical application of the psychological, social, and human mechanisms that make people and their interpersonal relationships a success in the sense of group cohesion. The main objective is to establish which are the tools and signals that can make a team leader identify group behavior problems and can redirect them, at the same time that he identifies the virtues such as team functioning and enhances and extends them.
\end{abstract}

Given that the expectations regarding the duration of mobility restrictions and social distancing due to the COVID-19 pandemic are in the medium / long term (there is no forecast of its remission in the short term), it is expected that the conclusions obtained in the present study may be used in the planning of the educational model for the next academic courses. In addition, it has taken advantage of the fact that the subject's fundamental focus is to work on the attitudes and skills necessary to efficiently manage group cohesion through interpersonal relationships, to deal with the assurance of the quality of education from the point of view of view of functioning as a group.

The conclusions obtained show that students see as very positive all initiatives for increasing the participation of students in class on a daily and continuous basis, using any accelerators for active participation. Any effort made for trying to save the social distancing (i.e., performing any face-to-face permitted activity) are also very well valued from students. The most requested initiative from students in order to improve the quality of university education at this time has been to put the focus on the effective learning (through practical activities in theoretical and practice classes) and effective evaluation (through practical cases analysis or any other way far different from the traditional question-answer evaluation method where it could seem to be even more important monitoring students so that they do not cheat rather than assessing their effective learning).

Keywords: Organizational Behavior; Change Management; Quality Education; Online Teaching; COVID-19.

\section{INTRODUCTION}

The objective of this study is, after almost half an academic year on the university campus of the Higher Polytechnic School of Alcoy (EPSA) with the theoretical and practical classes taught online (in a teaching environment traditionally developed completely face-to-face). face), obtain feedback from students on the aspects they most value as positive within the joint effort School-Teachers-Students to obtain quality teaching. 
This research work tries to bring valuable conclusions to the achievement of Sustainable Development Goal (SDG) number 4 defined as the United Nations (UN) as "Quality Education". The fact that the forecasts on the duration of the mobility restrictions due to the COVID-19 pandemic will be extended in time, indicates that these conclusions can be used in the planning of the educational model in the following academic year.

\subsection{Sustainable Development Goals (SDG)}

The United Nations (UN) is promoting, in line with the trend of promoting the sustainability of our way of life to achieve a better life for planet Earth and for future generations that inhabit it, an initiative called Sustainable Development Goals (SDG) focusing on "17 Goals to Transform Our World" [8]. The Sustainable Development Goals are a call for action by all countries to promote prosperity while protecting the planet. They recognize that ending poverty must go hand-in-hand with strategies that build economic growth and address a range of social needs including education, health, social protection, and job opportunities, while tackling climate change and environmental protection. More important than ever, the goals provide a critical framework for COVID-19 recovery [10]).

Among these SDGs [9], this work is circumscribed within the scope of "Goal 4: Quality Education" [7], where it's stated that "Education enables upward socioeconomic mobility and is a key to escaping poverty". Reinforcing the progress from last decades, towards increasing access to education and school enrollment rates at all levels, there is the need for correcting the actual dropout rate caused by the COVID-19 pandemic. In 2020, as the COVID-19 pandemic spread across the globe, a majority of countries announced the temporary closure of schools and universities spaces, impacting more than 91 per cent of students worldwide. Never before have so many students been out of academic world at the same time, disrupting learning and upending lives, especially the most vulnerable and marginalised. The global pandemic has far-reaching consequences that may jeopardize hard won gains made in improving global education.

The fundamental motivation of these SDG objectives focused on the quality of teaching, is to achieve a level of assurance of access for all students to any level of education, under equal conditions, and with the certainty of maximum use aimed at training professionals in guarantees that lead the world to a better future.

\section{2 “Organizational Behavior and Management of Change" University subject}

This research work has been developed within the academic frame of the university subject "Organizational Behavior and Change Management ", qualified as optative, with a load of 4.5 credits. This subject, placed in the 3rd year of the Degree in Informatics Engineering in the Universitat Politècnica de València (UPV), is also carried out in Escuela Politècnica Superior de Alcoi (EPSA), where the empirical study has been made in this case.

This subject has been chosen to carry out the study on how to improve the achievement of students in an online teaching environment due to mobility restrictions and social distancing. The main reason has been that the subject deals precisely with the management of personal expectations, within the triple personal-social-human sphere, which make the people who make up a certain group function as a team or as a cohesive and compact group. The teaching blocks and activities included within the course's teaching guide ensure that students can be induced to propose alternatives to improve the quality of teaching in these extreme circumstances in which a good management of personal expectations can lead to success in teaching with the highest quality.

Organizational Behavior $(\mathrm{OB})$ is the field of study of behavior and psychological processes in contexts related to work. Individual, group and organizational variables are part of the global scenario that may lead to improve performance [6]. What people do in an organization in order to facilitate the understanding of the complexity of the interpersonal relationships and people interactions, is the base to construct hypothesis about how that behavior affects the performance of the organization. It covers:

- individual variables: perception, learning and change of attitudes, motivation and satisfaction, design and stress at work;

- group variables: group work, group communication, leadership and conflict;

- organizational variables: politics, climate and culture and organizational change

The teaching guide of the subject includes the following competencies that should be gathered by the students at the end of the course: 
- Ability to understand and apply the principles of risk assessment and apply them correctly in the preparation and execution of action plans.

- Ability to integrate Information Technology and Communications solutions and business processes to meet the information needs of organizations, allowing them to achieve their objectives effectively and efficiently, thus giving them competitive advantages.

- Ability to understand and apply the principles and practices of organizations, so that they can act as a link between the technical and management communities of an organization and actively participate in the training of users.

- Locate relevant information from different sources and investigate technological developments in their field of work and related areas.

- Reason in an abstract, analytical and critical way, knowing how to elaborate and defend arguments in their area of study and professional field.

- Know how to apply their knowledge to their work or vocation in a professional way and possess the skills that are usually demonstrated through the elaboration and defense of arguments and the resolution of problems within their area of study.

With the profile of competencies described, and the general objective of the $\mathrm{OB}$ as a whole and as a definition, the approach of practical situations (and real, if possible) in which the student is in the process of evaluating a situational environment and taking action decisions in the three settings described by the variables (individual, group, and social), seems one of the educational and teaching options with the highest expectations of success ([4].

The study proposal, in which the students of the subject have participated, has been made based on the knowledge acquired, the life situations that occurred, and the hope that the conclusions obtained will help the entire university community in the following academic years . Next, the method followed for the study and the conclusions obtained are developed.

\section{METHODOLOGY}

This section describes how the structure of the study was designed, as well as the way in which the information was collected, and how the conclusions were reached.

\subsection{Research methodology}

This study aims to establish, after an online teaching course, in a university programmed for face-toface teaching, which would be the strengths to be promoted so that this type of teaching is successful and guarantees SDG number 4 "Quality Education ", while leaving aside or not putting more emphasis on those aspects of academic programming that have not helped or that have even hindered the achievement of this objective [2].

In order to receive feedback from a qualified working team, we have selected a subject group, in this case the third-year students (25 students) of the subject "Organizational Behavior and Change Management" at EPSA (once the 2020/2021 academic year has started). As the subject is an optative one, all the students have in common the selected subject but not the rest of the academic curriculum, so that it makes richer the conclusions due to the concurrence of homogeneous and heterogeneous factors.

To perform the study, we have taken advantage of several circumstances that concur in the selected work team:

- the academic maturity of third-year students of the Computer Engineering Degree, about to finish their university stage and enter the labor market (those who have not previously done so).

- the focus of the subject towards the management of the personal expectations of the members of the work teams in the companies.

- the triple dimension from which the subject works interpersonal relationships: individual (through psychology), group (through sociology) and human (through anthropology).

- the approach to the subject through Problem-Based Learning (PBL) that makes students jump into the analysis, debate, and management of real parameters in real situations $[3,5]$ and that therefore they are used to studying situations from a systemic, critical, and applied point of view. 
The selected sample has the limitation that it does not represent the entire educational community, but at the same time it has the virtue that it belongs to the branch of Business Management and that therefore it has been chosen by students whose professional expectations for the future include planning and management of the accelerators that make a group of people function compactly and as a team.

Once the work team has been selected, a form has been designed to obtain the information that can lead to valuable conclusions.

\subsection{Form design}

To request the statement of each student about their experience regarding what factors have been positive for the achievement of a quality education during the previous year, a form has been designed following the Likert scale [1] in the first part, and with an answer in open format in the second part.

The questions used for building the research form, were defined by a previous survey carried out at the end of the previous year 2019/2020, in which the students of the same subject were asked to give their first impressions of the success factors of the previous year. The designed form for the research that has been performed in year 2020/2021 is as follows.

Form Title: How can online teaching provide quality education in times of COVID-19?

Block $n^{\circ} 1$ (Likert scale questions): In the current online teaching environment imposed by the COVID pandemic, what factors help to maintain the level of quality of teaching?

Table 1. Form designed

\begin{tabular}{|l|l|l|l|l|l|}
\hline \multicolumn{1}{|c|}{ Statements } & $\begin{array}{c}\text { Fully } \\
\text { Agree }\end{array}$ & $\begin{array}{c}\text { Somewhat } \\
\text { Agree }\end{array}$ & Indifferent & $\begin{array}{c}\text { Somewhat } \\
\text { Disagree }\end{array}$ & $\begin{array}{c}\text { Fully } \\
\text { Disagree }\end{array}$ \\
\hline Continuous evaluation & & & & & \\
\hline $\begin{array}{l}\text { Put in value the interactive participation of } \\
\text { students in class }\end{array}$ & & & & & \\
\hline $\begin{array}{l}\text { Students and teacher are shown with the } \\
\text { camera live during classes }\end{array}$ & & & & & \\
\hline $\begin{array}{l}\text { Include (if possible) a face-to-face session } \\
\text { even if it is in open spaces }\end{array}$ & & & & & \\
\hline Adapt teaching materials to the online format & & & & & \\
\hline Adapt exams to online format & & & & & \\
\hline
\end{tabular}

Block $\mathrm{n}^{\circ} 2$ (open answer question): Propose measures or activities that, in the current environment, and taking into account the restrictions due to the COVID pandemic, could contribute improvements to achieve quality in university education.

The questionnaire has been delivered in electronic format to the 25 students so that they can answer it within a week, and thus be able to evaluate the results and draw conclusions that can be taken into account when planning the next courses.

\section{RESULTS}

After carrying out the empirical study, having passed the questionnaire during the 2020/2021 academic year at the Higher Polytechnic School of Alcoy (EPSA), with 25 students having been invited to answer, 22 of them have participated, representing the study sample a $88 \%$ of the global population, and making us accept the results as valid and representative.

The results are as follow for both Block 1 and Block2. In Table 1 the results for the Block 1 are shown in percentages, showing how many (in percentage) students have valued each statement with each Likert scale value. 
Table 2. Results from question about how the students see the value of each statement. Source: the authors.

\begin{tabular}{|l|c|c|c|c|c|}
\hline \multicolumn{1}{|c|}{ Statements } & $\begin{array}{c}\text { Fully } \\
\text { Agree }\end{array}$ & $\begin{array}{c}\text { Somewhat } \\
\text { Agree }\end{array}$ & Indifferent & $\begin{array}{c}\text { Somewhat } \\
\text { Disagree }\end{array}$ & $\begin{array}{c}\text { Fully } \\
\text { Disagree }\end{array}$ \\
\hline Continuous evaluation & $45.5 \%$ & $27.3 \%$ & $9.1 \%$ & $0 \%$ & $18.2 \%$ \\
\hline $\begin{array}{l}\text { Put in value the interactive participation of } \\
\text { students in class }\end{array}$ & $63.6 \%$ & $27.3 \%$ & $9.1 \%$ & $0 \%$ & $0 \%$ \\
\hline $\begin{array}{l}\text { Students and teacher are shown with the } \\
\text { camera live during classes }\end{array}$ & $36.4 \%$ & $9.1 \%$ & $54.5 \%$ & $0 \%$ & $0 \%$ \\
\hline $\begin{array}{l}\text { Include (if possible) a face-to-face session even } \\
\text { if it is in open spaces }\end{array}$ & $54.5 \%$ & $9.1 \%$ & $0 \%$ & $27.3 \%$ & $9.1 \%$ \\
\hline Adapt teaching materials to the online format & $63.6 \%$ & $27.3 \%$ & $0 \%$ & $0 \%$ & $9.1 \%$ \\
\hline Adapt exams to online format & $36.4 \%$ & $36.4 \%$ & $18.2 \%$ & $0 \%$ & $9.1 \%$ \\
\hline
\end{tabular}

The results from Block 1 show some direct facts that students have seen as very relevant in order to reach a high-quality learning in the special circumstances that we are living with COVID-19 restrictions:

- Most of the students see lot of value in the continuous evaluation: $45,5 \%$ fully agree and $27.3 \%$ somewhat agree on it, resulting that $72,8 \%$ of the students have good perception on it.

- Putting in value the interactive participation of students in class is one of the point with best value for the students. There are globally a $90,9 \%$ of good or excellent evaluation for that $(63,6 \%$ fully agree, and $27,3 \%$ somewhat agree).

- Most of the students $(54,5 \%)$ see as indifferent the value of showing the live camera during the online sessions. The rest of them see some point of value on it.

- The effort that could be done in order to perform any session face-to-face if possible, is valued by more than half of the students $(54,5 \%)$.

- Adapting the materials for online teaching is perhaps one of the more active claims by students (63,6\% fully agree, and $27,3 \%$ somewhat agree).

- Evaluation system being adapted to online environment appears also as one claim from students ( $72,8 \%$ in total raises this point as relevant).

The answers received for the question of Block 2 have been evaluated as remarkably interesting ones, and that makes us think of adding them as statements for evaluation in future studies. Students have proposed as interesting actions for improving the Quality Education in the actual social distancing academic environment:

- Encourage participation in online classes by promoting discussions, debates, group dynamics, games... between students and teacher. This proposal has appeared spontaneously by 7 students.

- Invite (to speaking in a practical class) someone who holds a relevant position in a company (some department head with people in charge), to be able to give a close vision of how workers are reacting, especially in our sector, to the telework issue, if there is more or better performance at the business level, how people feel and how they are managing being at home "alone" instead of in an office surrounded by colleagues.

- Controlling the workload is essential, since many students have difficulty concentrating due to the fatigue caused or even problems finding favorable situations and conditions for studying.

- Since in online exams many teachers are usually focused on not letting students cheat more than in evaluating the learning process of the students, the students would prefer to take practical exams (meaning to plan a global practical case where the students have to show all what they have learnt), instead of doing classical format exams with ugly rules for avoiding copying. This proposal has appeared spontaneously by 12 students.

- Group activities in open spaces such as the university garden, ...

The results from Block 2 show that there are two big requests from students, in order of preference: 
1 Prepare and perform more practical exams, through global cases, instead of the traditional exams.

2 Perform more debates and interactive sessions that make the students be actively involved in their own learning path.

\section{CONCLUSIONS}

As expected, the students have been massively involved in the development of the study, in which they have been offered the possibility of helping to design the springs that can compose the scenario of a quality university education in the times of COVID -19 , assuming the restrictions that this pandemic entails in terms of restricted mobility, social distancing, and the need to teach classes online and not in person.

The first major conclusion drawn from the study is that all the measures aimed at increasing the participation of students in class on a daily and continuous basis are well valued: promoting continuous evaluation and adequately assessing the active participation of students in class are two of the measures that enjoy great acceptance among the surveyed students.

The two measures aimed at promoting personal treatment have received different evaluations. On the one hand, students have not shown much enthusiasm (although they see a relatively positive measure) in encouraging video cameras to be open live during online video conferencing sessions. On the other hand, there has been a general consensus regarding the benefits of being able to give a face-to-face session if circumstances permit. This shows how relevant face-to-face education and the exchange of experiences that occur with interpersonal relationships in the university environment is for university students.

Any effort to adapt educational materials to the online format, as well as exams, has also been well valued by students, the latter question having been widely reinforced in the open response section.

The claim most massively proposed and endorsed by students, with a wide difference over the others, and also outstanding in both blocks of the study, has been: to prepare and perform exams in which, in a practical way, and through the global analysis of a practical case, the student shows the concepts they have learned, instead of using the traditional question-answer assessment methods in which it often seems more importantly to avoid the student copying rather than evaluating what he has actually learned.

The other great request on the part of students, to improve the level of quality of teaching, has been to use debates and group dynamics as the basis for learning, now and always, but even more in the context of online training.

Obviously, the study has the limitation that it has been carried out in a very localized environment, the students of a subject in a given course, although the subject and academic year have been carefully selected to ensure that the results are highly representative of what may be the general feeling of the students about what may be the most relevant efforts to achieve a quality education in the current environment.

\section{REFERENCES}

[1] Albaum, G. (1997). The Likert scale revisited. Market Research Society. Journal., 39(2), 1-21.

[2] Araújo, U. F., Fruchter, R., Garbin, M. C., Pascoalino, L. N., \& Arantes, V. (2014). The reorganization of time, space, and relationships in school with the use of active learning methodologies and collaborative tools. ETD: Educaçao Temática Digital, 16(1), 84-99

[3] Boud, D., \& Feletti, G. (2013). The challenge of problem-based learning. Routledge.

[4] Guerola-Navarro, V.; Oltra-Badenes, R.F.; Gil-Gómez, H.; \& Herrero-Casanova, M. (2019). Experience of external collaboration in Organizational Behavior and Change Management subject in practical lesson. In 12th International Conference of Education, Research and Innovation (ICERI 2019). (pp. 289 - 294). Sevilla, España: IATED.

[5] Ponsa, P., Amante, B., Román, J. A., Oliver, S., Díaz, M., \& Vives-Gràcia, J. (2009). Higher education challenges: introduction of active methodologies in engineering curricula. International Journal of Engineering Education, 25(4), 799-813 
[6] Robbins, S. P., Judge, T. A., \& Pineda Ayala, T. A. Comportamiento organizacional. México: Pearson Educación, 2013

[7] United Nations (UN) (2020a). Goal 4: Quality Education. Retrieved from: https://www.un.org/sustainabledevelopment/education/

[8] United Nations (UN) (2020b). Sustainable Development Goals. Retrieved from: https://www.un.org/sustainabledevelopment/

[9] United Nations (UN) (2020c). The Sustainable Development Goals: Our Framework for COVID-19 Recovery. Retrieved from: https://www.un.org/sustainabledevelopment/sdgs-framework-for-covid19-recoveryl

[10] World Health Organization (WHO) (2020). WHO Coronavirus Disease (COVID-19) Dashboard. Retrieved from: https://www.who.int/emergencies/diseases/novel-coronavirus-2019/question-andanswers-hub/q-a-detail/q-a-coronaviruses. 